\title{
A MÚSICA NO AMBIENTE EDUCACIONAL
}

Gabriela Lelis Euzito Silva ${ }^{1}$ Maxwell Ferreira Silva ${ }^{2}$

\section{RESUMO}

Com o objetivo de apresentar algumas das reflexões por intermédio dos processos de educação no século XXI, buscamos com o presente artigo alternativas para novas práticas pedagógicas, abordando algumas indagações propostas pela nova Base Comum Curricular (BNCC), estabelecidas pelo Ministério da Educação (MEC), em 2018, levando em consideração os processos e habilidades que a Música, mediante o seu ensino, práticas e vivências podem proporcionar aos educandos, potencializando o cognitivo e acrescentando valores no aprendizado, nas ações emocionais e sociais.

Palavras-chave: Educação. Música. Processos. Habilidades.

\begin{abstract}
In order to present some reflections on the education processes in the 21 st century, we seek with this article alternatives to new pedagogical practices, addressing some questions proposed by the new Common Curricular Base (BNCC), established by the Ministry of Education (MEC), in 2018, taking into account the processes and skills that Music, through its teaching, practices and experiences can provide students, enhancing cognitive and adding values in learning, emotional and social actions.
\end{abstract}

Keywords: Education. Music. Law Suit. Skills.

\section{RESUMEN}

Con el fin de presentar algunas reflexiones sobre los procesos educativos en el siglo XXI, buscamos con este artículo alternativas a las nuevas prácticas pedagógicas, abordando algunas preguntas propuestas por la nueva Base Curricular Común (BNCC), establecida por el Ministerio de Educación (MEC), en 2018, teniendo en cuenta los procesos y habilidades que la Música, a través de su enseñanza, prácticas y experiencias, puede proporcionar a los estudiantes, mejorando los valores cognitivos y agregando valores en el aprendizaje, las acciones emocionales y sociales.

Palabras clave: Educación. Musica. Procesos. Las habilidades.

\footnotetext{
${ }^{1}$ Mestrando em Ciências da Educação pela FICS - Facultad Interamericana de Ciencias Sociales, Especialista em Música e Artes pela Faculdade Futura, ICETEC, Brasil, Especialista em Musicoterapia pelo ISEAC - Instituto Superior de Educação de Afonso Cláudio, Graduada em Licenciatura em Música pelo CBM-CEU - Conservatório Brasileiro de Música-Centro Universitário/RJ, gabriela_musicista@hotmail.com

${ }^{2}$ Mestrando em Ciências da Educação pela FICS - Facultad Interamericana de Ciencias Sociales, Especialista em Música na Educação pela FACI - Faculdade de Tecnologia de Cachoeiro de Itapemirim, Especialista em Música e Artes pela FAVENI - Faculdade Venda Nova do Imigrante, Graduado em Licenciatura em Música pelo CBMCEU - Conservatório Brasileiro de Música-Centro Universitário/RJ, max_fsilva@hotmail.com
} 


\section{INTRODUÇÃO}

Vivemos em um mundo contemporâneo ao qual somos cercados de mudanças constantes no fazer cotidiano, rodeados pelas rupturas de valores, crenças, culturas, limites de tempo/espaço, e imersos em uma crescente globalização onde os sistemas de tecnologias estão cada vez mais inseridos na sociedade, fazendo com que estejamos em constante adaptação ao meio que estamos inseridos, e no ambiente educacional não se faz diferente.

Assim, essa pesquisa em forma de artigo, busca observar, analisar e refletir sobre essas mudanças nos processos de ensino educacional, argumentando a necessidade das instituições se adaptarem as novas transformações de seus educandos, buscando um ambiente para a troca de saberes, valorizando as diferentes culturas sociais e o docente como influente atuante nas ações do ensino. Como um agente mediador para esse processo educacional, refletimos sobre a importância da Música e suas vivências como parte de uma metodologia ativa nas instituições, contribuindo para o aprimoramento de habilidades cognitivas e emocionais, podendo ser um aliado para a formação dos discentes.

\subsection{OBJETIVO}

Contribuir através de pesquisas para a valorização da Música e suas habilidades nos ambientes educacionais, buscando o crescimento dos educandos por meio de uma educação efetiva que valoriza além das contribuições cognitivas, as questões sociais e emocionais dos discentes.

\subsection{METODOLOGIA}

Trata-se de pesquisa em cunho bibliográfico, onde, buscou-se analisar citações, metodologias e reflexões em sites científicos como Scielo, Google Acadêmico e universidades, além de livros e artigos com publicações entre os anos de 1997 a 2018, utilizando descritores como: Paulo Freire, Rubem Alves, Marisa Trench de Oliveira Fonterrada, Maria de Lourdes Sekeff Zampronha, Alfredo Veiga-Neto, dentre outros. A pesquisa se direciona mediante a valorização da música no ambiente educacional, sua importância para a agregação por meio da miscigenação cultural e suas relevâncias nos processos de habilidades socioemocionais, citando as benfeitorias adquiridas pelo seu ensino. Com tudo, este artigo irá citar pensamentos e metodologias diante de renomados pesquisadores. 


\section{VALORIZAÇÃO DA MÚSICA NA EDUCAÇÃO}

Segundo os Parâmetros Curriculares Nacionais (PCN, 1997), toda ação humana envolve uma atividade corporal e a criança, que é um ser em constante mobilidade, utiliza-se dela para buscar conhecimento de si mesma e daquilo que a rodeia, relacionando-se sempre com objetos e pessoas. A ação é necessária para que a criança harmonize de maneira integradora as potencialidades motoras, afetivas e cognitivas, assim, ela se movimenta nas ações do seu cotidiano.

Podemos dizer que ainda em fase de gestação, as mães utilizam da música, mesmo que de forma involuntária, para estabelecer um elo com seu bebê que depois de nascido, poderá ser acalentado por canções de ninar. Essa ligação com a música pode o acompanhar durante todo o seu processo de desenvolvimento. Logo nos primeiros meses de vida, é possível notar as movimentações com estímulos musicais, que aparecem de forma espontânea quando são expostos a algum tipo de música e à medida que vão crescendo esses movimentos poderão ir se tornando cada vez mais coordenados e eles passam a adquirir um maior controle de seu corpo. Recebendo estes estímulos musicais desde pequenos, quando maiores, eles, provavelmente, irão cantar suas músicas favoritas enquanto brincam ou inventarão canções para qualquer atividade. É comum, em um ambiente com crianças, notarmos a presença de cantigas e brincadeiras de roda por diversas vezes, pois a vivência com a música pode se tornar algo natural e recorrente no seu dia a dia. Correr, pular, girar e subir nos objetos são algumas das atividades dinâmicas que podem estar ligadas à sua necessidade de experimentar o corpo não só para seu domínio, mas na construção de sua autonomia e movimentação.

Quando adolescente, a música pode ter um importante papel na formação da identidade pessoal; podendo revelar características importantes do seu ser e sua personalidade interpessoal, podendo ou não o acompanhar durante todo o seu crescimento.

A vivência musical é um fator que pode contribuir, de forma mais integral, para a expressão dos sentimentos ou opiniões de cada pessoa, acrescentando valores na subjetividade do indivíduo. É uma forma de ampliar o desenvolvimento global, o processo de ensinoaprendizagem e a cognição, abrangendo toda a complexidade e a pluralidade do ser humano, abarcando também o campo social e afetivo.

Segundo o Educador Musical japonês Shinichi Suzuki (1898 - 1998), as pessoas são produto de seu meio, ou seja, somos o fruto de tudo o que vivenciamos no decorrer da vida. Para Suzuki, este pensamento também se direciona à vivência musical, ao qual deve-se fazer presente durante toda a infância da criança, como ocorre com sua língua materna, onde os pais 
e o meio ao qual a criança convive a direciona ao contato com a língua. Desta forma, se a música for estimulada precocemente na vida da criança, ela aprenderá de forma natural, do mesmo modo com que ela aprende a língua do seu país. Para Suzuki “...toda criança, potencialmente, tem capacidade para aprender música, do mesmo modo que para aprender a falar a língua de seu país - sua língua mãe. "(FONTERRADA, 2008, p. 165). Suzuki pergunta:

Como?! Todas as crianças japonesas falam japonês! Esse pensamento foi para mim como um relâmpago numa noite escura. ... se elas falam tão fácil e fluentemente o japonês, deve haver algum segredo no seu aprendizado. Realmente, todas as crianças do mundo são educadas por um método perfeito: por sua língua materna (FONTERRADA, 2008, p. 167).

Apesar da música estar presente em nosso meio, por vezes de forma subjetiva, nos apropriamos das vivências musicais informais que nos rodeiam, assim surgem levantamentos ao qual podem ser cabíveis sua reflexão, visando um melhor entendimento sobre esse "poder" da música em relação ao desenvolvimento humano. Qual o valor da música? Qual é o seu papel perante a sociedade contemporânea brasileira?

A educadora musical Marisa Fonterrada (2008), em seu livro "De tramas e fios: Um ensaio sobre música e educação", inicia seu diálogo explanando sobre a importância de se conhecer sobre a valorização e importância da música perante a sociedade antes mesmo de se conhecer sobre a educação musical.

Assim, em sua grande maioria, é comum obter respostas sobre esses questionamentos a músicos instrumentistas, educadores musicais, estudantes de música, entre outros que já atuam na área, e ainda assim encontrarmos muitas polivalências ao seu respeito e principalmente ao seu uso, o que é apropriado ou não. Mas se o valor da música é unânime entre os músicos, não seria pertinente em outros segmentos da sociedade?

É importante a adoção e um pensar filosófico como norteador de atitudes e escolhas, pois ele se constitui a partir de valores, e estabelece conexões entre os diversos elementos que compõem o conjunto de pressupostos a respeito da natureza e do valor de determinado campo de estudos (FONTERRADA, 2008, p. 11).

Discorrendo sobre o assunto, Fonterrada ressalta que o fator da música ter ou não seu valor reconhecido, a coloca diretamente dentro ou fora do currículo escolar, isso depende inteiramente do quanto é ou não considerada pelo grupo social. Abordando que, se em determinada cultura, a música for uma das grandes influenciadoras e disciplina no saber individual do ser, o valor da educação musical também será elevado, assim como em outros campos de conhecimento. Em contrapartida, se não houver esse reconhecimento musical e sua 
sobreposição em relação há outras áreas de conhecimento, a educação musical também será tratada como banal. Podendo ser esta a grande questão ao qual nos deparamos em relação a música, e talvez explique a grande polivalência de pensamentos em relação a educação musical nas escolas regulares de ensino. "Esta é a questão crucial com que se depara hoje no Brasil: o resgate do valor da música perante a sociedade, único modo de recoloca-la no processo educacional. " (FONTERRADA, 2008, p. 13).

Assim, o impacto que a música pode ter diante da sociedade está entrelaçado, em grande parte, com o entendimento do que ela pode oferecer. Por isso se faz necessário o aprofundamento em estudos que embasem as razões e que justifiquem a presença da música nas escolas, não somente de forma aleatória ou como auxiliar em aulas de outras disciplinas, como auxilio em boas práticas, mas efetivamente como educação musical.

\footnotetext{
Até que se descubra seu real papel, até que cada indivíduo em particular, e a sociedade como um todo, se convençam de que ela é uma parte necessária, e não periférica, da cultura humana, até que se compreenda que seu valor é fundamental, ela terá dificuldades para ocupar um lugar proeminente no sistema educacional (FONTERRADA, 2008, p. 12).
}

\section{MISCIGENAÇÃO CULTURAL NA EDUCAÇÃO E MÚSICA}

“... inexiste validade no ensino de que não resulta um aprendizado em que o aprendiz não se tornou capaz de recriar ou refazer o ensinado, em que o ensinado que não foi apreendido não pode ser realmente aprendido pelo aprendiz" (FREIRE, 2013, P. 26).

No mundo contemporâneo ao qual vivemos, cercados por mudanças constantes ao longo da história social e pedagogicamente para o ambiente educacional, as instituições de ensino necessitam estar atentas a essas transformações, que acontecem no decorrer do cotidiano e que por sua vez, podem passar desapercebidas e ocasionar possíveis transtornos nos currículos escolas. Uma vez que a escola é, socialmente, um lugar neutro para a troca do saber, juntamente com a miscigenação na troca de culturas sociais, sendo um ambiente de formação na subjetividade formal dos educandos.

O mundo contemporâneo está vivendo uma outra ruptura radical nas formas de significar, representar e usar o espaço e o tempo, que se constituem em condições de possibilidade para fenômenos sociais, políticos, culturais e econômicos que até há pouco ainda eram inexpressivos ou desconhecidos, como a globalização, a exacerbação da diferença, a fantasmagoria, o hipercontrole, o hiperconsumo, a volatilidade etc., (VEIGA - NETO, 2002, p. 167). 
Acabamos por viver imersos nas constantes mudanças, onde as noções espaciais, temporais, limites e fronteiras estão quebrando seus paradigmas, os valores culturais já não são mais os mesmos. Estamos sujeitos a valorização das diversas mobilidades e da velocidade ao qual as informações são acarretadas através das demasiadas tecnologias, sejam elas nos espaços de lazer, trabalho, práticas cotidianas, e no ambiente escolar não se faz diferente, o que coloca os educandos em um espaço de adequações. Assim, é papel das instituições de ensino fazer com que essas mudanças sejam subtendidas e vivenciadas de forma prática aos seus discentes, atendendo suas necessidades acadêmicas e sociais.

Chegou a hora de fazer mais além de reformar nossos métodos e práticas. Chegou a hora de questionar as suposições modernistas nas quais estes métodos e práticas se baseiam e de desenvolver uma nova perspectiva que simultaneamente rejeite, transforma e preserve o que existe (DOLL, 1997, p. 27 apud SANTOS, 2012, p. 238).

Paulo Freire (2013), em seu livro Pedagogia da autonomia: saberes necessários à prática educativa, nos deixa entendido a necessidade do educador em refletir e pensar em suas práticas pedagógicas, mas porque não repensar essas práticas como um modelo educacional? Não necessariamente uma prática educacional de Paulo Freire, mas uma prática onde os educandos possam ser inquiridores do seu meio e participarem ativamente dos processos de seu ensino. Assim, pondera sobre algumas indagações a serem refletidas:

\footnotetext{
Por que não discutir com os alunos a realidade concreta a que se deva associar a disciplina cujo conteúdo se ensina, a realidade agressiva em que a violência é a constante e a convivência das pessoas é muito maior com a morte do que com a vida? Por que não estabelecer uma "intimidade" entre os saberes curriculares fundamentais aos alunos e a experiência social que eles têm como indivíduos? Por que não discutir as implicações políticas e ideológicas de um tal descaso dos dominantes pelas áreas pobres da cidade? A ética da classe embutida neste descaso? (FREIRE, 2013, p. 32).
}

Ainda sobre as indagações, Freire reflete que o professor e ou, amplamente a escola, possui o dever de não somente respeitar, mas também discutir sobre os saberes populares que os educandos adquirem com a vida social, construídos na prática do seu dia a dia, discutindo com os discentes as razões desses saberes informais com o ensino dos conteúdos acadêmicos permeando-os um com o outro e tornando-os significativos para a vida do aluno. Em resposta a suas perguntas, o próprio as responde, "Porque, dirá um educador reacionariamente pragmático, a escola não tem nada que ver com isso. A escola não é partido. Ela tem que ensinar os conteúdos, transferi-los aos alunos. Aprendidos, estes operam por si mesmos. " (FREIRE, 2013, p. 32). 
Contrário a este pensamento, o educador deve ter como ânsia para sua prática docente, elevar e aprimorar a capacidade crítica dos seus educandos, sua curiosidade e a habilidade em recriar o que se é apreendido e não deixar que sua prática se torne somente a de transferir conteúdo.

Rubem Alves (2010) explana em seu livro Conversas sobre educação, a importância de fomentar a vontade de aprender nos educandos, deixando explicito que qual seria a necessidade de se "aprender" tantos conteúdos acadêmicos, sendo que os mesmos, dependendo da forma ao qual são ensinados, podem não ser alinhados com a vida cotidiana do aluno. Em comparação ao dito popular que diz: "É fácil levar a égua até o meio do ribeirão. O difícil é convencê-la a beber a água...” Alves a aplica para educação dizendo: "É fácil obrigar o aluno a ir à escola. O difícil é convencê-lo a aprender aquilo que ele não quer aprender...” (ALVES, 2010, p. 25).

Sua preocupação está no fato das instituições forçarem os alunos a beberem a água que elas não querem beber, forçarem a aprender um conteúdo que por vez pode ser insignificante ao educando naquele momento ao qual está sendo aprendido, o que não significa que o conteúdo não seja importante, mas tudo advém da maneira ao qual é transmitido.

Por vez, essas reflexões e anseios para mudanças metodológicas e curriculares nem sempre são fáceis a serem colocadas em prática, pois demandam de uma série de modificações e persistência para que as mudanças sejam efetivadas e que se tenham resultados práticos, isso por tirar os principais articuladores do seu "meio de conforto".

Estar no limite do risco, ou arriscar, supõe enxergar o que está embaralhado ou oculto em nós. Formados no projeto moderno, não é fácil escapar das práticas de uma pedagogia desenvolvida sobre os critérios da modernidade. É convidativo seguir o caminho prescrito, já traçado, previsto, tomado como "ideal", e que expressa o desejo de evitar os riscos (SANTOS, 2012, p. 230).

Na obra Música, cultura e Educação (2012), organizada por Regina Márcia Simões Santos envolvendo diversos pesquisadores da área, compreendemos o que é currículo e seu papal na escola, expondo que todo sujeito que vive e participa de um ambiente é formador de um processo de identidades, sendo o conjunto um currículo social com a participação de todos que se fazem presentes no meio. Assim a escola está inserida nesse meio social dos indivíduos, se tornando um lugar formador de identidades, de processos de subjetivação, que pode ser um fator importante para a formação do caráter e personalidade dos sujeitos, um lugar de referências. Sendo o currículo um conjunto de diversos processos, para Tomaz Tadeu da Silva, não é suficiente tratar das diversidades com respeito ou tolera-las, na medida em que elas estão presentes no meio social é preciso analisa-las e compreende-las para um currículo multicultural. 
Um currículo inspirado nessa concepção não se limitaria, pois, a ensinar a tolerância e o respeito, por mais desejável que isso possa parecer, mas insistiria, em vez disso, numa análise dos processos pelos quais as diferenças são produzidas através de relações de assimetria e desigualdade. Num currículo multiculturalista crítico, a diferença, mais do que tolerada ou respeitada, é colocada permanentemente em questão (SILVA, 2009, p. 88 - 89).

Segundo Elizabeth Travassos (2005), a música acarreta poderes para distinguir e ao mesmo tempo unir, podendo ser uma abertura para produções de identidades culturais, sendo realizada individualmente ou em grupos. Nas escolas ela pode ser um grande aliado para formação das subjetividades, onde os educandos se identifiquem em grupos, práticas e hábitos, acarretando valores e significados as produções musicais.

\begin{abstract}
Uma das constatações paradoxais a respeito da música é ela ser, simultaneamente, o que une e o que separa. A música congrega e identifica - daí sua presença obrigatória nos rituais que celebram a comunhão de um grupo social e seu potencial de discriminação entre "nós" e os "outros". Ela também diferencia, classifica e hierarquiza - daí a força com que distingue e mesmo estigmatiza, particularmente nas sociedades de classes. A música "unanimiza" (conforme uma ideia apreciada por Mário de Andrade) e é, ao mesmo tempo, a mais "classante" das artes - na expressão de Pierre Bourdieu (BOURDIEU, 1979, p. 17 apud TRAVASSOS, 2005, p. 11).
\end{abstract}

\title{
4. A MÚSICA COMO FERRAMENTA SOCIOEMOCIONAL
}

Desde o final do século XX em diante, a sociedade vem sendo marcada por grandes mudanças sociais e culturais, modificando suas relações cotidianas e interpessoais, fazendo com que tenhamos que lidar com novos conhecimentos e informações a todo instante.

A universalização dos meios de comunicação está a cada dia mais acessível a todos os públicos, em qualquer faixa etária, e os mecanismos para o entretenimento e informatização buscam de forma crescente o aperfeiçoamento de aparelhos que se adequam nas diversas faixas cognitivas levando informações e conhecimento de forma rápida e prática.

No meio educacional não é diferente, a educação precisa estar preparada para as novas relações ao qual o mundo está vivendo e se adequar para uma geração informatizada que estar suscetível as transformações, desenvolvendo aptidões imprescindíveis para que seus educandos possam aprender, conviver e trabalhar em um mundo cada vez mais competitivo e complexo em todas as vertentes. Segundo a psicopedagoga Anita Lilian Zuppo Abed, em entrevista à Revista Educação,

...não há como preparar as crianças e jovens para enfrentar os desafios do século XXI sem investir no desenvolvimento de habilidades para selecionar e processar informações, tomar decisões, trabalhar em equipe, resolver problemas, lidar com as emoções (ABED, 2018 apud INFORME PUBLICITÁRIO, 2018). 
A consciência de que o mundo está em constante transformação e que a tecnologia embarga como parte presente nesse crescimento, faz com que as instituições de ensino, que é parte fundamental no desenvolvimento pessoal e influenciadora na formação do indivíduo, esteja preparada para formar cidadãos que saibam os conhecimentos curriculares, mas que também sejam capazes de lidar com as emoções de forma potencializada, sendo cidadãos críticos e formadores de opiniões.

Baseando-se que o aprender não envolve somente as contribuições cognitivas, mas também as questões emocionais e sociais, o MEC estabeleceu uma nova Base Nacional Comum Curricular (BNCC) que estabelece propostas que trazem, em sua boa parte, competências gerais que se baseiam no desenvolvimento de habilidades socioemocionais. $\mathrm{O}$ intuito é que todas as instituições de ensino, sejam elas públicas ou privadas, estabelecem os valores empregados na BNCC, para que o país tenha um ensino crescente conforme as mudanças atuais.

\begin{abstract}
A Base Nacional Comum Curricular (BNCC) é um documento de caráter normativo que define o conjunto orgânico e progressivo de aprendizagens essenciais que todos os alunos devem desenvolver ao longo das etapas e modalidades da Educação Básica, de modo a que tenham assegurados seus direitos de aprendizagem e desenvolvimento, em conformidade com o que preceitua o Plano Nacional de Educação (PNE). Este documento normativo aplica-se exclusivamente à educação escolar, tal como a define o $\S 1^{\circ}$ do Artigo $1^{\circ}$ da Lei de Diretrizes e Bases da Educação Nacional (LDB, Lei $n^{\circ}$ 9.394/1996)1, e está orientado pelos princípios éticos, políticos e estéticos que visam à formação humana integral e à construção de uma sociedade justa, democrática e inclusiva, como fundamentado nas Diretrizes Curriculares Nacionais da Educação Básica (BRASIL, 2018, p. 7).
\end{abstract}

Segundo a BNCC (2018), competências é entendida como a mobilização do conhecimento através de conceitos e procedimentos, as habilidades são as práticas cognitivas e socioemocionais, onde ambas as práticas competências/habilidades são integradoras para que os educandos possam ter valores e atitudes em resolver demandas complexas no cotidiano, assim estimulando ações que contribuam para a transformação da sociedade, tornando-a socialmente mais justa e humana. Tendo em vista que o envolvimento do educando/escola está muito além dos ensinos acadêmicos e a transmissão do conhecimento, as competências buscam trazer saberes que poderá conduzir ao educando um conjunto de vivências que visam uma acrescente capacidade no poder de lidar com o pensamento crítico, argumentações, autonomia, empatia, diversidade, comunicação, criatividade, dentre outras capacidades necessárias para uma vida pensante no século 21 , acarretado com suas constantes mudanças.

Assim, foram criadas 10 (dez) Competências Gerais da Educação Básica:

1. 


\begin{tabular}{|c|c|}
\hline 2. & $\begin{array}{l}\text { Exercitar a curiosidade intelectual e recorrer à abordagem própria das ciências, incluindo a } \\
\text { investigação, a reflexão, a análise crítica, a imaginação e a criatividade, para investigar } \\
\text { causas, elaborar e testar hipóteses, formular e resolver problemas e criar soluções (inclusive } \\
\text { tecnológicas) com base nos conhecimentos das diferentes áreas. }\end{array}$ \\
\hline 3. & $\begin{array}{l}\text { Valorizar e fruir as diversas manifestações artísticas e culturais, das locais às mundiais, e } \\
\text { também participar de práticas diversificadas da produção artístico-cultural. }\end{array}$ \\
\hline 4. & $\begin{array}{l}\text { Utilizar diferentes linguagens - verbal (oral ou visual-motora, como Libras, e escrita), } \\
\text { corporal, visual, sonora e digital -, bem como conhecimentos das linguagens artística, } \\
\text { matemática e científica, para se expressar e partilhar informações, experiências, ideias e } \\
\text { sentimentos em diferentes contextos e produzir sentidos que levem ao entendimento mútuo. }\end{array}$ \\
\hline 5. & $\begin{array}{l}\text { Compreender, utilizar e criar tecnologias digitais de informação e comunicação de forma } \\
\text { crítica, significativa, reflexiva e ética nas diversas práticas sociais (incluindo as escolares) } \\
\text { para se comunicar, acessar e disseminar informações, produzir conhecimentos, resolver } \\
\text { problemas e exercer protagonismo e autoria na vida pessoal e coletiva. }\end{array}$ \\
\hline 6. & $\begin{array}{l}\text { Valorizar a diversidade de saberes e vivências culturais e apropriar-se de conhecimentos e } \\
\text { experiências que lhe possibilitem entender as relações próprias do mundo do trabalho e fazer } \\
\text { escolhas alinhadas ao exercício da cidadania e ao seu projeto de vida, com liberdade, } \\
\text { autonomia, consciência crítica e responsabilidade. }\end{array}$ \\
\hline 7. & $\begin{array}{l}\text { Argumentar com base em fatos, dados e informações confiáveis, para formular, negociar e } \\
\text { defender ideias, pontos de vista e decisões comuns que respeitem e promovam os direitos } \\
\text { humanos, a consciência socioambiental e o consumo responsável em âmbito local, regional } \\
\text { e global, com posicionamento ético em relação ao cuidado de si mesmo, dos outros e do } \\
\text { planeta. }\end{array}$ \\
\hline 8. & $\begin{array}{l}\text { Conhecer-se, apreciar-se e cuidar de sua saúde física e emocional, compreendendo-se na } \\
\text { diversidade humana e reconhecendo suas emoções e as dos outros, com autocrítica e } \\
\text { capacidade para lidar com elas. }\end{array}$ \\
\hline 9. & $\begin{array}{l}\text { Exercitar a empatia, o diálogo, a resolução de conflitos e a cooperação, fazendo -se respeitar } \\
\text { e promovendo o respeito ao outro e aos direitos humanos, com acolhimento e valorização } \\
\text { da diversidade de indivíduos e de grupos sociais, seus saberes, identidades, culturas e } \\
\text { potencialidades, sem preconceitos de qualquer natureza. }\end{array}$ \\
\hline 10. & $\begin{array}{l}\text { Agir pessoal e coletivamente com autonomia, responsabilidade, flexibilidade, resiliência e } \\
\text { determinação, tomando decisões com base em princípios éticos, democráticos, inclusivos, } \\
\text { sustentáveis e solidários. }\end{array}$ \\
\hline
\end{tabular}

Segundo Maria Helena Guimarães, Secretária Executiva do Ministério da Educação, em entrevista ao Site Educador 360.

As competências do século XXI dizem respeito a formar cidadãos mais críticos, com capacidade de aprender a aprender, de resolver problemas, de ter autonomia para a tomada de decisões; cidadãos que sejam capazes de trabalhar e equipe, respeitar o outro, o pluralismo de ideias, que tenham a capacidade de argumentar e defender seu ponto de vista... (GUIMARÃES, 2017 apud SOCIOEMOCIONAIS, 2017).

Assim, as competências socioemocionais, se fazem presentes no texto das 10 (dez) competências básicas para a educação propostas pela BNCC, especialmente nos últimos 5 
(cinco) itens da lista, tornando o espaço educativo um ambiente com discentes ativos no próprio ensino, criativos e críticos, influenciando o ambiente ao qual estarão inseridos. O educando deixa de ser um mero receptor de informações e passa a atuar diretamente no meio pessoal e no grupo como um todo. Essa importância de que o aluno não é somente um "receptor de informações" já é alvo de debates no meio educacional por muitos estudiosos, como indaga Paulo Freire em seu livro Pedagogia da autonomia: saberes necessários à prática educativa

Saber que ensinar não é transferir conhecimento, mas criar as possibilidades para a sua própria produção ou a sua construção. Quando entro em uma sala de aula devo estar sendo um ser aberto a indagações, à curiosidade, às perguntas dos alunos, a suas inibições; um ser crítico e inquiridor, inquieto em fase da tarefa que tenho - a de ensinar e não a de transferir conhecimento (FREIRE, 2013, p. 47).

Desta forma as competências socioemocionais, sendo potencializadas na fase educacional, o indivíduo a levará por toda a vida, contribuindo com as mudanças na sociedade.

\begin{abstract}
No novo cenário mundial, reconhecer-se em seu contexto histórico e cultural, comunicar-se, ser criativo, analítico-crítico, participativo, aberto ao novo, colaborativo, resiliente, produtivo e responsável requer muito mais do que o acúmulo de informações. Requer o desenvolvimento de competências para aprender a aprender, saber lidar com a informação cada vez mais disponível, atuar com discernimento e responsabilidade nos contextos das culturas digitais, aplicar conhecimentos para resolver problemas, ter autonomia para tomar decisões, ser proativo para identificar os dados de uma situação e buscar soluções, conviver e aprender com as diferenças e as diversidades (BRASIL, 2018, p. 14).
\end{abstract}

Sobre a ênfase nos aspectos socioemocionais como forma de aprimoramento essencial para a educação no século XXI, o Instituto Ayrton Senna em seu artigo publicado sobre as Competências Socioemocionais, indaga sobre quatro aprendizagens que são fundamentais para um ser humano mais preparado para enfrentar os conflitos do mundo. Sendo: aprender a ser, aprender a conviver, aprender a conhecer e aprender a fazer. Onde todas podem ser trabalhadas nos aspectos socioemocionais.

Na mesma direção, o Relatório para a UNESCO da Comissão Internacional sobre Educação para o Século 21, organizado por Jacques Delors, sintetiza a Educação para o século 21 em quatro aprendizagens que concorrem para a formação de um ser humano mais preparado para enfrentar os desafios de um mundo com contornos ainda incertos. São elas: aprender a ser, aprender a conviver, aprender a conhecer e aprender a fazer. Conhecidas como "quatro pilares da educação", essas aprendizagens traduzem uma concepção integradora de educação, que pode ser aprimorada pela aplicação concreta em escolas e realidades locais (SENNA, Instituto Ayrton, p. 5). 
Contudo, torna-se evidente a necessidades das instituições de ensino se preparem e adaptarem para novas práticas pedagógicas que atendam às necessidades de seus educandos, abordando as indagações proposta pela BNCC. Assim, o estudo da música e sua vivência é um fator que pode contribuir para a prática com experiências socioemocionais, uma vez que seu estudo bem trabalhado e orientado por profissionais capacitados na área da música, além do seu estudo propriamente dito, pode contribuir na capacidade de comunicação, a expressão dos sentimentos ou opiniões, aprimoramento da imaginação, o fazer artístico, a criatividade, inibição, consciência auditiva, equilíbrio emocional, dentre outras competências que podem por si, contribuir e acrescentar valores na subjetividade do indivíduo. Assim como a educadora Maria de Lourdes Sekeff Zampronha explana.

\begin{abstract}
Música não é somente um recurso de combinações e exploração de ruídos, sons e silêncios, em busca do chamado gozo estético. Ela é também um recurso de expressão (de sentimentos, ideias, valores, cultura, ideologia), um recurso de comunicação (do indivíduo consigo mesmo e com o meio que o circunda), de gratificação (psíquica, emocional, artística), de mobilização (física, motora, afetiva, intelectual) e autorrealização (o indivíduo com aptidões artístico-musicais mais cedo ou mais tarde direciona-se nesse sentido, seja criando - compondo, improvisando -, recriando interpretando, tocando, cantando, "construindo" uma nova parição -, ou simplesmente apreciando - vivenciando o prazer da escuta) (ZAMPRONHA, 2007, p. 14).
\end{abstract}

É uma forma de ampliar o desenvolvimento global, o processo de ensino-aprendizagem e a cognição, uma vez que o fazer musical pode-se tornar uma linguagem com diversos sentidos e que interage diretamente com o nosso corpo, nossos sentidos e emoções, pois é exatamente nesses sentidos em que ela se cria, abrangendo toda a complexidade e a pluralidade do ser humano, abarcando também o campo social e afetivo.

\title{
5. CONSIDERAÇÕES FINAIS
}

Observa-se que as práticas com as vivências musicais podem acarretar aos indivíduos diversas benfeitorias no fazer cognitivo, emocional e social. Uma vez que a mesma se faz presente em todos os meios sociais, por vezes de forma subjetiva, mas sempre há algum convívio com sonoridades, timbres e elementos da música ao qual sendo bem trabalhados e por profissionais capacitados, podem se transformar em grandes aliados, através da educação musical, para a formação integral dos educandos, visto que suas práticas, podem formar indivíduos mais sensíveis sonoramente com uma consciência auditiva, agregando valores ao que os rodeiam, sendo expressivos emocionalmente, criativos e formadores de opiniões. 
Entende-se que, todos esses processos e reflexões analisadas acerca das modificações necessárias no sistema educacional, não são fáceis de serem colocadas em vigor, é um processo gradual e que demandam de muita persistência para que sejam colocadas efetivamente em prática e assim obter os resultados esperados. Por fim, é de suma importância as pesquisas, reflexões e análises dos processos que estão sendo realizados e das possíveis metodologias que ainda podem ser colocadas em prática.

\section{REFERÊNCIA}

ALVES, Rubem. Conversas sobre educação / org. por Raissa Castro. 10ª edição. Campinas, São Paulo: Verus Editora, 2010.

BRASIL. Ministério da Educação. Base Nacional Comum Curricular, BNCC. Brasília: MEC, 2018.

BRASIL. Secretaria de Educação Fundamental. Parâmetros Curriculares Nacionais: arte. Brasília: MEC/SEF, 1997.

COMO os sistemas de ensino trabalham as habilidades socioemocionais. Revista Educação, 08 de março de 2018. Disponível em: https://www.revistaeducacao.com.br/como-os-sistemasde-ensino-trabalham-as-habilidades-socioemocionais/. Acesso em: 25 de mai. de 2019.

COMPETÊNCIAS socioemocionais: Material de discussão. Educação sec.21, Instituto Ayrton Senna. Disponível em: http://educacaosec21.org.br/wpcontent/uploads/2013/07/COMPET\%C3\%8ANCIASSOCIOEMOCIONAIS_MATERIALDE-DISCUSS\%C3\%83O_IAS_v2.pdf. Acesso em: 27 de abr. de 2019

FREIRE, Paulo. Pedagogia da Autonomia: Saberes necessários à prática educativa. 47 edição. Rio de Janeiro: Paz e Terra, 2013.

FONTERRADA, Marisa Trench de Oliveira. De tramas e fios: um ensino sobre música e educação. $2^{\text {a }}$ edição. São Paulo: Editora UNESP; Rio de Janeiro: Funarte, 2008.

SANTOS, Regina Marcia Simão Santos (org). Música, cultura e educação: os múltiplos espaços de educação musical. $2^{\text {a }}$ edição. Porto Alegre: Sulina, 2012.

SILVA, Tomaz Tadeu da. Documentos de identidade: uma introdução às teorias do currículo. $3^{\mathrm{a}}$ edição. Belo Horizonte: Autêntica, 2009.

SOCIOEMOCIONAIS e a BNCC: Como adequar a sua escola? Gestão escolar, Mapeamento Curricular Socioemocional. Educador 360. Disponível em: https://educador360.com/gestao/socioemocionais-bncc-como-adequar/. Acesso em: 13 de abr. de 2019.

TRAVASSOS, Elizabeth. Apontamentos sobre estudantes de música e suas experiências formadoras. Revista da ABEM, Porto Alegre, v. 12, p. 11 - 19, 2005. 
VEIGA-NETO, Alfredo. De geometrias, currículo e diferenças. Educação e Sociedade, Campinas, $\mathrm{n}^{\circ}$ 79, p. $163-186,2002$.

ZAMPRONHA, Maria de Lourdes Sekeff. Da música, seus usos e recursos. $2^{\mathrm{a}}$ edição. Revista e ampliada. São Paulo: Editora UNESP, 2007. 